\title{
ITR-284 modulates cell differentiation in human chronic myelogenous leukemia K562 cells
}

\author{
JAI-SING YANG ${ }^{1}$, CHAO-YING LEE ${ }^{2}$, HSIN-CHUNG CHO ${ }^{3}$, CHI-CHENG LU ${ }^{1,4}$, SHENG-CHU KUO ${ }^{5,6}$, \\ YEN-FANG WEN $^{7}$, FUU-JEN TSAI ${ }^{8-10}$, MIAU-RONG LEE ${ }^{11}$ and SHIH-CHANG TSAI ${ }^{3}$ \\ ${ }^{1}$ Department of Medical Research, China Medical University Hospital, China Medical University; \\ ${ }^{2}$ School of Pharmacy, China Medical University; ${ }^{3}$ Department of Biological Science and Technology, \\ China Medical University, Taichung; ${ }^{4}$ Department of Pharmacy, Buddhist Tzu Chi General Hospital, Hualien; \\ ${ }^{5}$ Chinese Medicinal Research and Development Center, China Medical University Hospital, \\ China Medical University; ${ }^{6}$ School of Pharmacy, China Medical University, Taichung; \\ ${ }^{7}$ Medicinal Chemistry Laboratory, Biomedical Engineering Research Laboratories, \\ Industrial Technology Research Institute, Hsinchu; ${ }^{8}$ Genetics Center, Department of Medical Research, \\ China Medical University Hospital; ${ }^{9}$ School of Chinese Medicine, China Medical University; \\ ${ }^{10}$ Department of Medical Genetics, China Medical University Hospital; \\ ${ }^{11}$ Department of Biochemistry, China Medical University, Taichung, Taiwan, R.O.C.
}

Received May 23, 2017; Accepted October 30, 2017

DOI: 10.3892/or.2017.6090

\begin{abstract}
ITR-284 is a carboxamide analog that can inhibit proliferation in human promyelocytic leukemia HL-60 cells. To understand the effects and molecular mechanisms of ITR-284 in human erythromyeloblastoid leukemia, we treated K562 cells with different concentrations of ITR-284 (0, 2, 4, 6, 8 and $10 \mathrm{nM})$ and all-trans retinoic acid (ATRA) (0, 0.1, 0.5, 1,5 and $10 \mu \mathrm{M}$ ) for $24 \mathrm{~h}$. The $\mathrm{IC}_{50}$ of ITR-284 was $\sim 10 \mathrm{nM}$ in K562 cells treated for $24 \mathrm{~h}$ as determined by MTT assay. May-Grünwald-Giemsa staining and nitro blue tetrazolium (NBT) assays were used to determine cell morphology changes and differentiation after ITR-284 and ATRA treatment. In addition, mRNA expression levels of hematopoietic factors, including GATA-1,NF-E2 and GATA-2, were elevated, while expression levels of $B C R-A B L$ were downregulated in $\mathrm{K} 562$ cells after $24 \mathrm{~h}$ of treatment with ITR-284 as determined by quantitative reverse transcription polymerase chain reaction. In addition, western blot analyses showed that FOXM1, GLI 1 and c-MYC protein levels were decreased by ITR-284. Taken together, our data show that ITR-284 induced K562 cell differentiation, which led to decreased tumorigenesis. Our findings suggest that ITR-284 could be a potential candidate for treating chronic myelogenous leukemia.
\end{abstract}

Correspondence to: Dr Shih-Chang Tsai, Department of Biological Science and Technology, China Medical University, 91 Hsueh-Shih Road, Taichung 40402, Taiwan, R.O.C.

E-mail: sctsai@mail.cmu.edu.tw

Key words: ITR-284, chronic myelogenous leukemia, K562 cells, cell differentiation, all-trans retinoic acid

\section{Introduction}

Chronic myelogenous leukemia (CML) is a cancer of the blood cells and bone marrow $(1,2)$. This myeloproliferative disorder is predominantly diagnosed in adults and is characterized by uncontrolled cell growth (3). The exact cause of CML remains elusive. CML is associated with the Philadelphia chromosome, which is a reciprocal chromosome translocation and fusion of the BCR gene on chromosome 22 and the ABL gene on chromosome 9 (4-6). The resulting BCR-ABL fusion protein possesses constitutive kinase activity and promotes the unregulated proliferation of hematopoietic stem cells $(5,7)$.

The properties of differentiation and self-renewal in hematopoietic stem cells are modulated by various lineagespecific transcription factors $(8,9)$. Consensus DNA sequences for the family of GATA transcription factors can be found in the promoters of many hematopoietic linkage-related genes, including $\beta$-globin $(10,11)$. GATA binding protein 1 (GATA-1) and nuclear factor, erythroid derived 2 (NF-E2) are specifically involved in the transcriptional regulation of terminal differentiated erythroid cells $(12,13)$. In contrast, GATA binding protein 2 (GATA-2) and myeloproliferative leukemia virus oncogene (c-MPL) are required for the expansion of multipotential hematopoietic progenitors and the formation of mast cells but not for the terminal differentiation of erythroid cells and macrophages $(14,15)$. c-MYC has been found to be involved in growth, differentiation and apoptosis $(16,17)$. During erythroid and myelomonocytic differentiation, c-MYC plays a critical role. The overexpression of c-MYC leads to the partial inhibition of erythroid differentiation in K562 cells (18-21). In addition, c-MYC suppresses the differentiation induced by imatinib in chronic myeloid leukemia cells (22-24). BCR-ABL kinase inhibitors, such as imatinib and dasatinib, have been used to successfully treat CML $(22,23)$. 
ITR-284 [N-(2-dimethylaminoethyl)-4,8-dihydrobenzo (1,2-b;4,5-b') dithio-phene-2-carboxamide phosphoric acid salt], a carboxamide derivative, exhibits potent anticancer effects on various human cancer cell lines (25-27). Our previous study indicated that ITR-284 had anti-proliferative effects on HL60 and WEHI-3 leukemia cells, but it had very low toxicity toward normal cells $(26,27)$. ITR-284 also showed growth inhibitory effects on human hepatocellular cancer cell lines (HepG2, Hep3B, SK-HEP-1 and J5) and colorectal cancer cell lines (HT-29, COLO-205, HCT-116 and SW-620) (26). In this study, we investigated the efficacy of ITR-284 in treating myeloid leukemia and compared its induction of human chronic myelogenous leukemia K562 cell differentiation with that of all-trans retinoic acid (ATRA).

\section{Materials and methods}

Chemicals and reagents. Fetal bovine serum (FBS), L-glutamine, penicillin-streptomycin, and RPMI-1640 medium were obtained from Thermo Fisher Scientific Inc. (Grand Island, NY, USA). All-trans retinoic acid (ATRA), 3-(4,5-dimethylthiazol-2-yl)-2,5-diphenyltetrazolium bromide (MTT), May-Grünwald stain and nitro blue tetrazolium were purchased from Sigma (Sigma, St. Louis, MO, USA). Primary antibodies against FOXM1, GLI 1, c-MYC, BCL-2, caspase-3 and $\beta$-actin were purchased from GeneTex (Hsinchu, Taiwan). ITR-284 was synthesized by Dr Yen-Fang Wen at China Medical University.

Cell culture. Human chronic myelogenous leukemia cell line K562 was obtained from the American Type Culture Collection and grown in RPMI-1640 supplemented with $10 \%$ fetal bovine serum (FBS), $100 \mathrm{U} / \mathrm{ml}$ penicillin and $100 \mu \mathrm{g} / \mathrm{ml}$ streptomycin. Cells were passaged every two days and maintained in a humidified environment with $95 \%$ air and $5 \% \mathrm{CO}_{2}$ at $37^{\circ} \mathrm{C}$ for the following experiments $(5,28,29)$.

Cell viability assay. Cell viability was determined by MTT assay. Briefly, K562 cells were seeded at $1 \times 10^{4}$ cells per well in 96-well plates (Costar, Corning Inc., Corning, NY, USA), allowed to attach overnight, and then exposed to various concentrations of ITR-284 $(0,2,4,6,8$ and $10 \mathrm{nM})$ or ATRA $(0,0.1,0.5,1,5$ and $10 \mu \mathrm{M})$ for $24 \mathrm{~h}$. The culture media was removed, and $100 \mu \mathrm{l}$ of $0.5 \mathrm{mg} / \mathrm{ml}$ MTT solution was added to each well. After $4 \mathrm{~h}$ of incubation at $37^{\circ} \mathrm{C}$, the supernatant was removed, and $100 \mu \mathrm{l}$ of DMSO was added to each well. The absorbance at $595 \mathrm{~nm}$ was measured by using an enzyme-linked immunosorbent assay reader, and the control absorbance was normalized to $100 \%$. Six replicate wells were included in each group, and at least three independent experiments were done $(23,25,30)$.

Trypanblueexclusionassayforcell death.Cells were treated with ITR-284 and cell death was evaluated by trypan blue exclusion assay as previously described (31). Briefly, K562, HL60, U937 and WEHI- 3 cells were seeded in a $24-$ well plate $\left(2.5 \times 10^{5}\right.$ cells/ per well) and were incubated with ITR-284 as indicated. After $24 \mathrm{~h}$, cells were stained with $0.25 \%$ trypan blue solution and the amount of dead cells were determined by Countess Automated Cell Counter (Invitrogen/Life Technologies) (31).
Terminal deoxynucleotidyl transferase dUTP nick end labeling (TUNEL) staining. Apoptotic DNA fragmentation was detected using In Situ Cell Death Detection kit, Fluorescein (Roche, Mannheim, Germany) according to the manufacturer's protocol. Briefly, K562 cells ( $2 \times 10^{5}$ cells/per well) were seeded into 12-well plates and incubated with $0,5,10$ and $15 \mu \mathrm{M}$ of ITR-284 for 48 h. Cells were harvested and assayed by In Situ Cell Death Detection kit, Fluorescein (31).

May-Grünwald Giemsa staining. May-Grünwald Giemsa (MGG) staining was used to analyze the morphological features of megakaryocytes. Approximately, $5 \times 10^{4}$ cells were seeded in each well of a 24 -well plate for $24 \mathrm{~h}$ and treated with ITR-284 and ATRA at the indicated concentrations for another $24 \mathrm{~h}$. Cells were centrifuged onto a microscope slide at $800 \mathrm{x} \mathrm{g}$ for $5 \mathrm{~min}$ and fixed with $10 \%$ formaldehyde. After air drying, the slides were stained with May-Grünwald solution (Sigma) for $5 \mathrm{~min}$; the solution was removed, and the cells were then stained with Giemsa solution for another $20 \mathrm{~min}$. The stained cells were examined, and images were captured with an inverted microscope (Nikon Eclipse TE2000U) (9).

Cell differentiation. Nitro blue tetrazolium (NBT) reduction assay is used to determine the differentiation of blood leukocytes by measuring the production of alkaline phosphatase. Briefly, $1 \times 10^{5}$ cells were seeded in each well of a 24-well plate for $24 \mathrm{~h}$ and treated with ITR-284 and ATRA at the indicated concentrations for another $24 \mathrm{~h}$. Cells were centrifuged into a $1.5-\mathrm{ml}$ microscope tube at $6000 \mathrm{x} \mathrm{g}$ for $5 \mathrm{~min}$ and washed with $1 \mathrm{ml}$ of PBS. After centrifugation, the cell pellets were mixed with NBT reagent for $5 \mathrm{~min}$ at $37^{\circ} \mathrm{C}$ and then stained with NBT for $10 \mathrm{~min}$ at room temperature. The proportion of blue-stained cells was calculated using a total of 200 cells randomly selected for each sample in triplicate by light microscopy. The mean $\pm \mathrm{SD}$ of a representative experiment is shown $(8,32)$.

RNA extract. Approximately $1 \times 10^{5}$ cells from each treatment were harvested. Total RNA was isolated using the TRIzol reagent (Invitrogen, USA) according to the manufacturer's instructions. Briefly, cell pellets were treated with $1 \mathrm{ml}$ of TRIzol at room temperature for $5 \mathrm{~min}$; next, $0.2 \mathrm{ml}$ of chloroform was added to the tubes and mixed well. After centrifugation at 12,000 rpm for $15 \mathrm{~min}$, the upper aqueous layers were transferred to new tubes and mixed with $0.5 \mathrm{ml}$ of isopropanol for $10 \mathrm{~min}$. The tubes were centrifuged at $12,000 \mathrm{rpm}$ for $15 \mathrm{~min}$. The pellets were dried and dissolved in DEPC-treated $\mathrm{H}_{2} \mathrm{O}$. Absorbance was measured at 260 and $280 \mathrm{~nm}$. A ratio of A260:A280 between 1.8 and 2.0 was used to verify the purity of the samples $(29,33,34)$.

Quantitation of gene expression by real-time RT-PCR. Quantitative RT-PCR was performed according to the Takara One Step SYBR Ex Taq ${ }^{\mathrm{TM}}$ qRT-PCR kit. Briefly, one-step RT-PCR was performed in a $20-\mu 1$ reaction volume containing $100 \mathrm{ng}$ of total RNA, 8 pmol of each forward and reverse primer, Prime Script 1 Step Enzyme Mix, 2X one-step SYBR RT-PCR buffer and RNase-free $\mathrm{dH}_{2} \mathrm{O}$. Quantitative RT-PCR was performed on an ABI 7900HT system (Applied Biosystems). Quantitative RT-PCR conditions were as follows: 
A

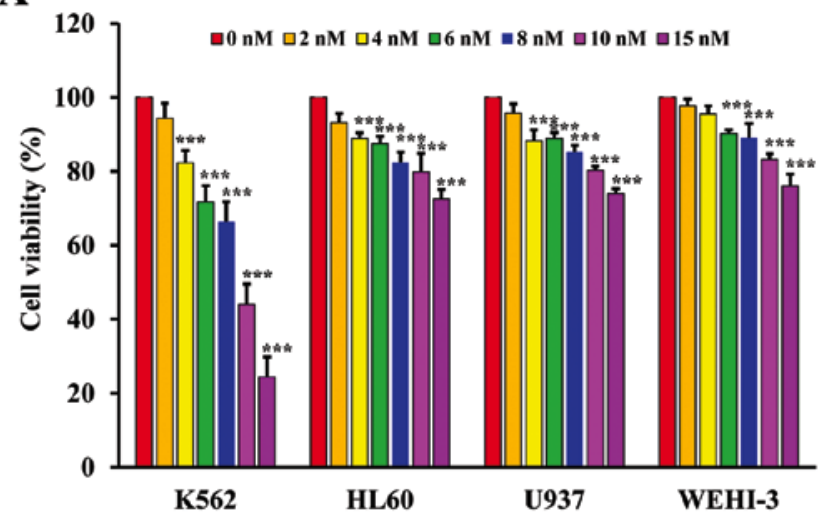

C

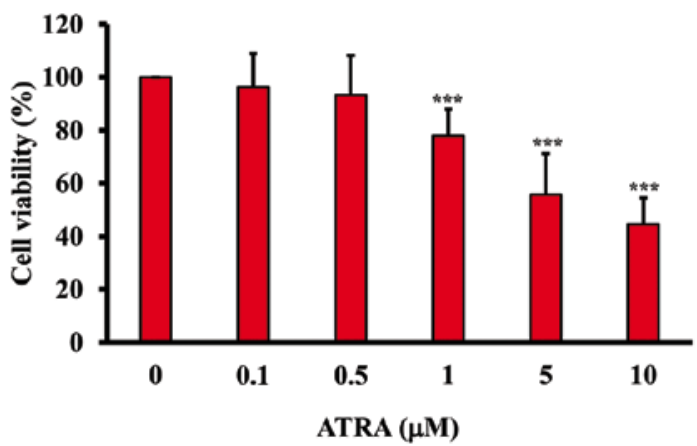

B

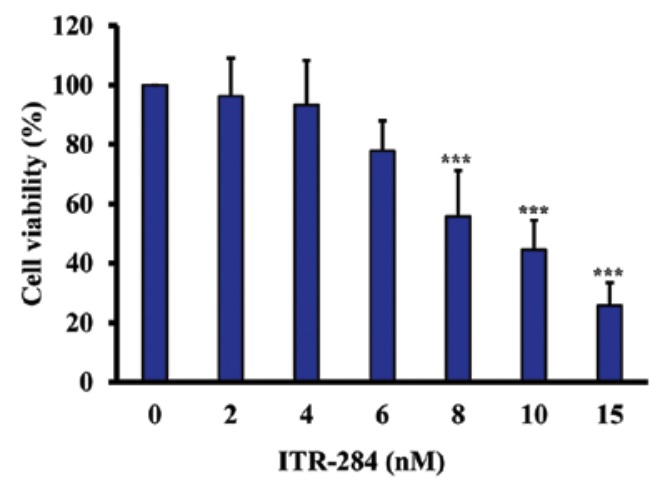

D
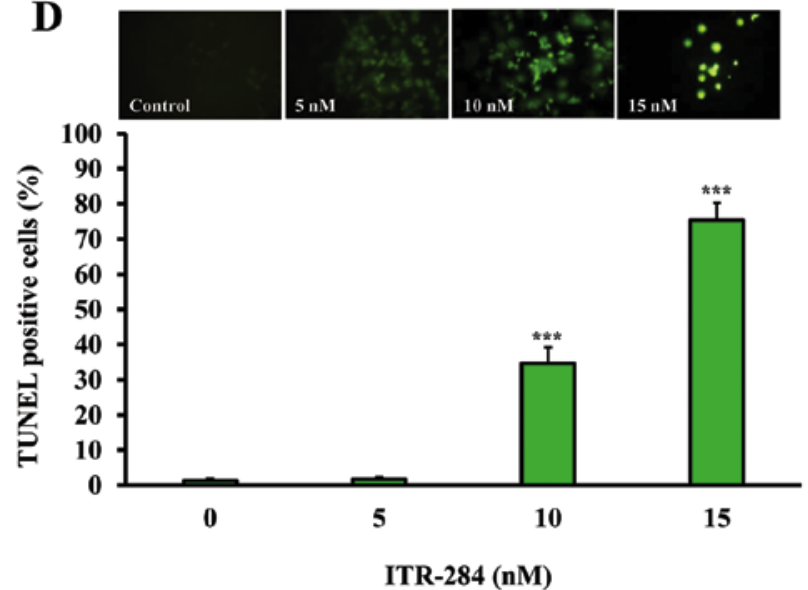

Figure 1. ITR-284 and ATRA have an inhibitory effect on K562 cell viability. (A) K562, HL60, U937 and WEHI-3 cells were treated with different concentrations of ITR-284 for $24 \mathrm{~h}$. Cell viability was determined by trypan blue exclusion assay. K562 cells were treated with ITR-284 (B) or ATRA (C) for $24 \mathrm{~h}$. Cell viability was determined by MTT assay. The $\mathrm{IC}_{50}$ values of ITR-284 and ATRA were $\sim 9 \mathrm{nM}$ and $8.5 \mu \mathrm{M}$, respectively $\left({ }^{* * * *} \mathrm{p}<0.005\right)$. (D) K562 cells were treated with higher concentrations of ITR-284 for $24 \mathrm{~h}$. Apoptosis was determined by TUNEL assay.

stage 1 was cDNA synthesis at $42^{\circ} \mathrm{C}$ for 5 min and then denaturation at $95^{\circ} \mathrm{C}$ for $10 \mathrm{~min}$. Stage 2 was RT-PCR amplification for 40 cycles, denaturation at $94^{\circ} \mathrm{C}$ for $30 \mathrm{sec}$ and annealing and elongation at $60^{\circ} \mathrm{C}$ for $15 \mathrm{sec}$. The relative expression level of target genes was determined by normalizing the RNA concentration to that of the $\beta$-actin internal control. The relative expression levels of mRNA represent the mean \pm SD of duplicates. The primer sequences used for quantitative RT-PCR were as follows: i) actin,forward: 5'-CCAACCGCGAG AAGATGA3' and reverse: 5'-TCCATCACGATGCCAGTG-3'; ii) GATA-1, forward: 5'CTGAGGGCTTGGATGCAG-3' and reverse: 5'-TGGGTACACCTGAAAGACTGG-3'; iii) GATA-2, forward: 5'-TGGCGCACAACTACATGG-3' and reverse: 5'-GCGAGTCGAGGTGATTGAAG-3'; iv) NF-E2, forward: 5'-GCTGTCCACTTCAGAGCTAGG-3' and reverse: 5'-GCTC ACTTGAGACATTCAGA-3'; v) c-mpl, forward: 5'-CCTCTTC ATGGTCACCTCCT-3' and reverse: 5'-AGGAGACATCTTGG CTGCTG-3'; vi) c-myc, forward: 5'-CGGTGCAGCCGTATT TCTAC-3' and reverse: 5'-CAGCAGCTCGAATTTCTTCC-3'; and vii) BCR-ABL, forward: 5'-CACAGCATTCCGCTGACC ATCA-3' and reverse: 5'-GCTTCACACCATTCCCCATTGT-3' $(29,33,34)$.

Statistical analysis. All data are presented as the mean \pm standard deviation (SD). One-way analysis of variance (ANOVA) with a one-tailed Student's t-test was used for multiple comparisons among groups. A value of $\mathrm{p}<0.05$ was considered statistically significant $(5,33,35)$.

\section{Results}

ITR-284 and ATRA inhibit cell viability of K562 cells. The trypan blue exclusion assays were performed to investigate the cytotoxic effects of ITR-284 on several leukemic cell lines including K562, HL60, U937 and WEHI-3 (Fig. 1A). K562 cells were more sensitive than other cells. We investigated the cytotoxic effects of ITR-284 and ATRA on the proliferation of K562 cells by the MTT assays. ITR-284 (Fig. 1B) and ATRA (Fig. 1C) inhibited the viability of K562 cells in a concentration-dependent manner. The $\mathrm{IC}_{50}$ values of ITR-284 and ATRA were $9 \mathrm{nM}$ and $8.5 \mu \mathrm{M}$, respectively. When $\mathrm{K} 562$ cells were treated with concentrations which were higher than $\mathrm{IC}_{50}$, we were able to observe apoptotic cells using TUNEL assays (Fig. 1D).

Morphological changes in ITR-284- and ATRA-treated K562 cells. The May-Grünwald-Giemsa staining method was used to observe the morphological changes and differentiation of blood cells via microscopy. ITR-284-treated cells had morphological changes at concentrations $>6 \mathrm{nM}$. Cells were differentiated 


\section{A}
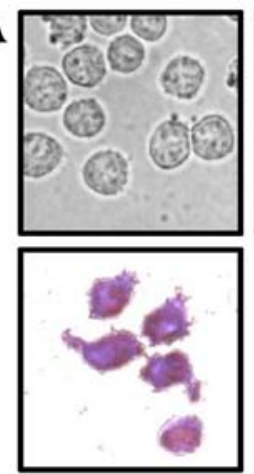

Control

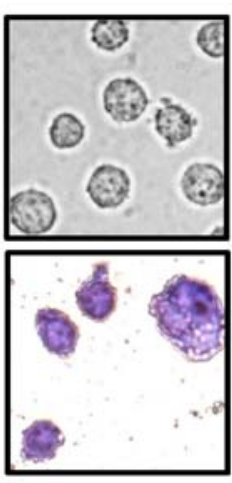

$2 \mathrm{nM}$

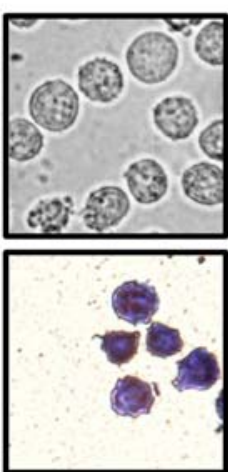

$4 \mathrm{nM}$

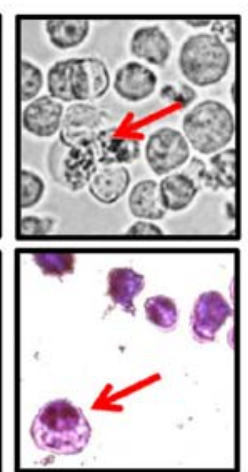

$6 \mathrm{nM}$

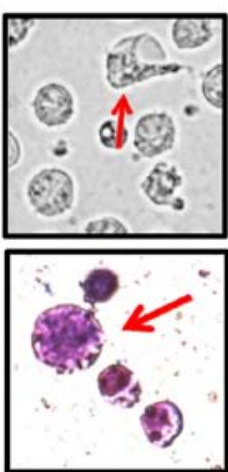

$8 \mathrm{nM}$

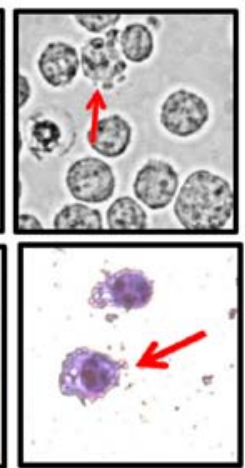

$10 \mathrm{nM}$

ITR-284; 24 h; x400

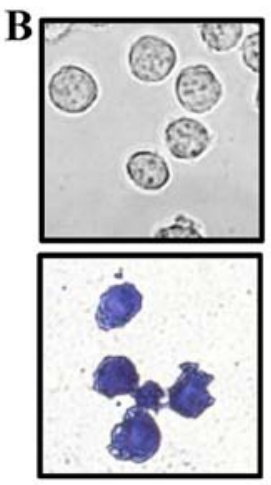

Control

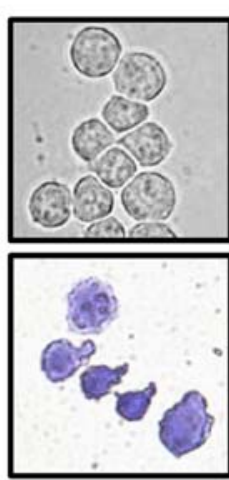

$0.10 \mu \mathrm{M}$

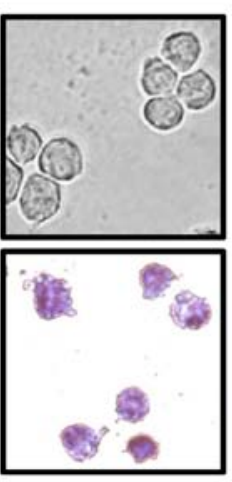

$0.25 \mu \mathrm{M}$

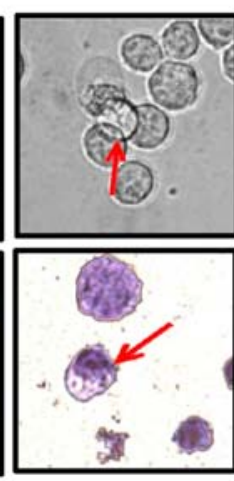

$0.50 \mu \mathrm{M}$

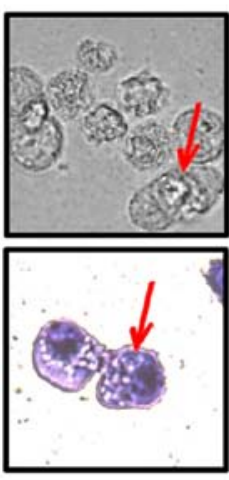

$0.75 \mu \mathrm{M}$
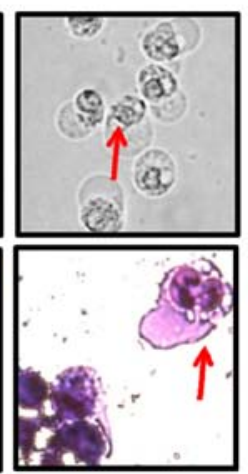

$1.00 \mu \mathrm{M}$

ATRA; 24 h; $\mathbf{x 4 0 0}$

Figure 2. Morphological changes in K562 cells treated with ITR-284 and ATRA. K562 cells were treated with ITR-284 (A) or ATRA (B) for 24 h and then stained with May-Grünwald-Giemsa solution. Photomicrographs of the cells were taken using an inverted microscope at x400 magnification. Megakaryocytic features, such as an increase in the nuclear size and cytoplasmic mass, were observed (as indicated by the arrow) for treatment with the higher concentrations of ITR-284 or ATRA.

A

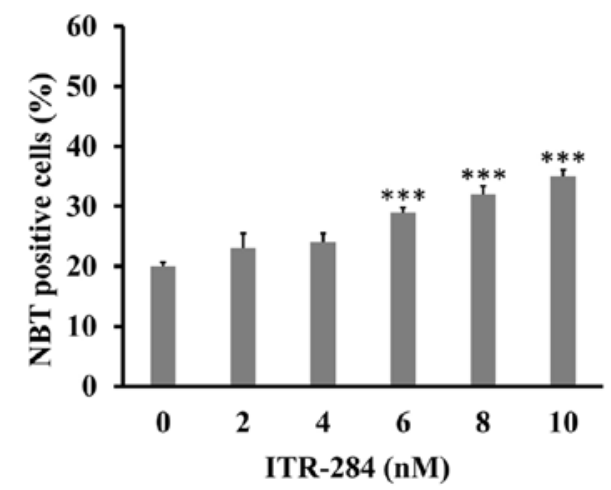

B

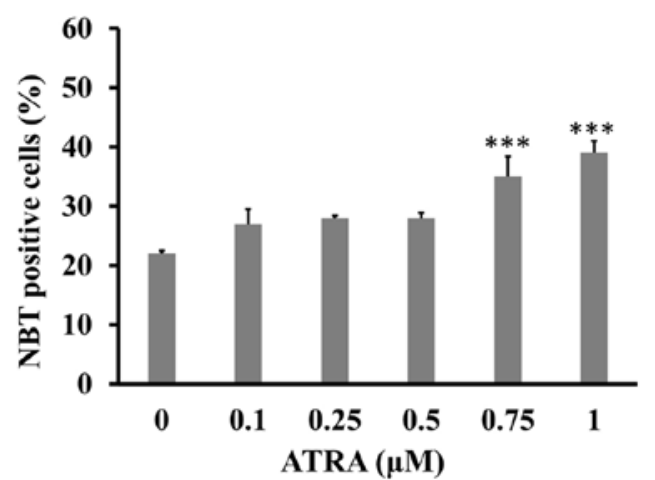

Figure 3. Effects of ITR-284 and ATRA on cell differentiation in K562 cells. K562 cells were treated with ITR-284 (A) or ATRA (B) as indicated for 24 h; then, nitro blue tetrazolium was added for analysis. A total of 200 cells were counted for each sample in triplicate using light microscopy. The proportion of NBT-positive (blue-stained) cells was calculated $\left({ }^{* * *} \mathrm{p}<0.005\right)$.

and showed the nuclei characteristics of white blood cells, not those of red blood cells (Fig. 2A). Likewise, ATRA-284 treated cells had morphological changes at concentrations $>0.5 \mu \mathrm{M}$. More nuclei were observed in ATRA-284-treated cells than in ITR-284-treated cells (Fig. 2B). Furthermore, to examine whether ITR-284 and ATRA promote cell differ- entiation, we used the nitro blue tetrazolium (NBT) assay to detect the production of alkaline phosphatase. NBT was used as a substrate for alkaline phosphatase, which converted the yellow NBT dye to purple-blue formazan in cells. After treatment with either ITR-284 or ATRA for $24 \mathrm{~h}$, the K562 cells had differentiated significantly (Fig. 3). 

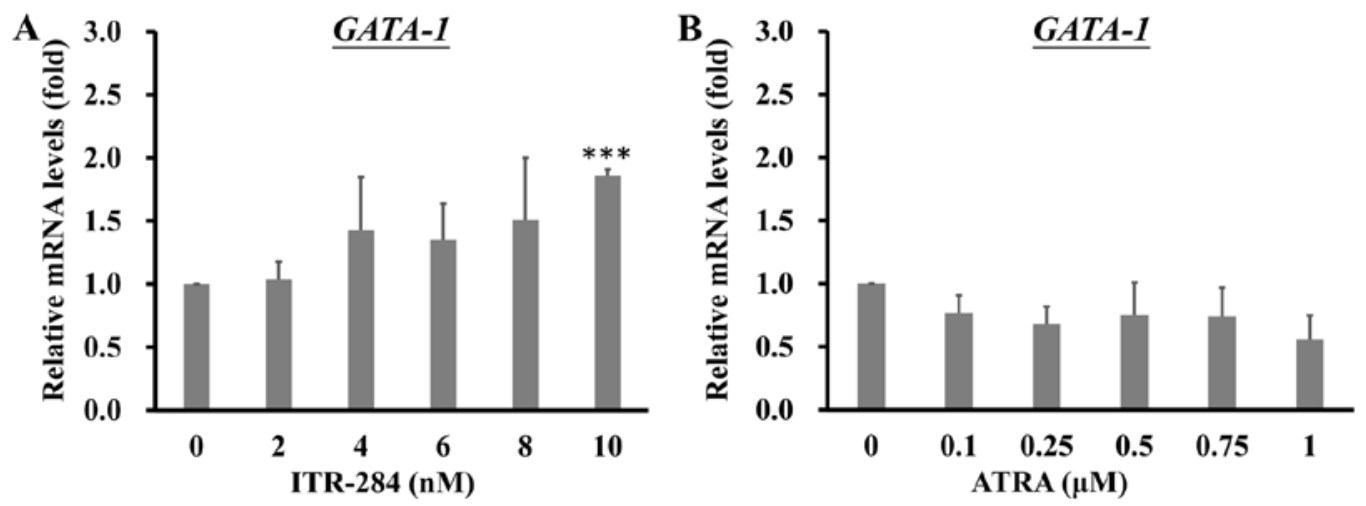

Figure 4. ITR-284 induces GATA-1 mRNA expression in K562 cells. K562 cells were treated with ITR-284 (A) or ATRA (B) as indicated for $24 \mathrm{~h}$. RNA was extracted from each sample, and GATA-1 mRNA expression levels were evaluated by quantitative RT-PCR. ITR-284 increased GATA-1 mRNA expression levels, while no significant change was observed in ATRA-treated K562 cells $\left({ }^{* * * *} \mathrm{p}<0.005\right)$.
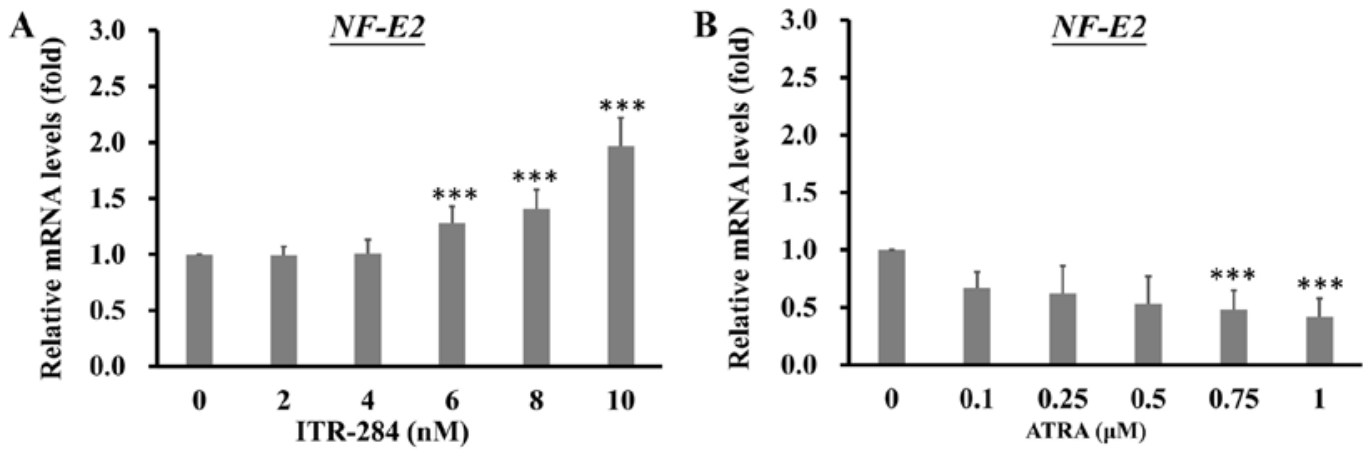

Figure 5. ITR-284 regulates NF-E2 mRNA expression in K562 cells. K562 cells were treated with ITR-284 (A) or ATRA (B) as indicated for 24 h. RNA samples were extracted; then, quantitative RT-PCR was performed to analyze the expression levels. The $N F-E 2$ mRNA expression levels were increased in ITR-284-treated K562 cells but decreased in ATRA-treated K562 cells $\left({ }^{* * *} \mathrm{p}<0.005\right)$.
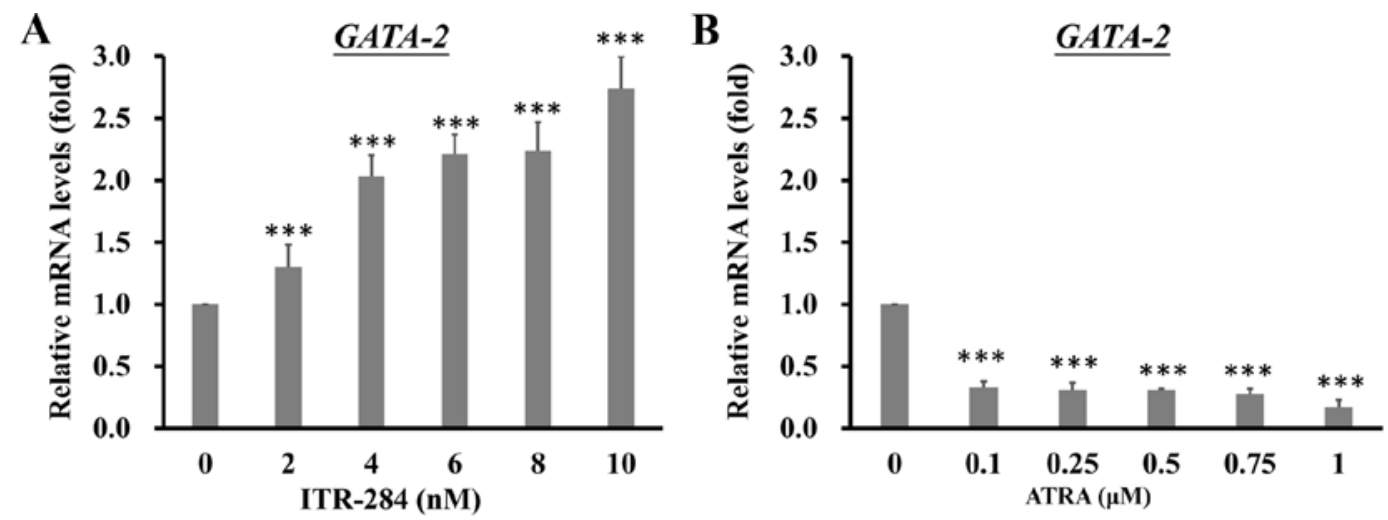

Figure 6. ITR-284 induces GATA-2 mRNA expression in K562 cells. K562 cells were treated with ITR-284 (A) or ATRA (B) as indicated for 24 h. RNA was extracted from each sample, and GATA-2 mRNA expression levels were evaluated by quantitative RT-PCR. The GATA-2 mRNA expression levels were increased in ITR-284-treated K562 cells but decreased in ATRA-treated K562 cells $\left({ }^{* * * *} \mathrm{p}<0.005\right)$.

ITR-284 and ATRA regulated GATA-1 and NF-E2 $m R N A$ expression. To determine the relationship of GATA transcription factors and EF-E2 in ITR-284- and ATRA-induced cell differentiation, we examined the mRNA expression levels of GATA-1 and NF-E2 by quantitative RT-PCR. GATA-1 (Fig. 4A) and $N F-E 2$ (Fig. 5A) mRNA levels increased in the ITR-284-treated K562 cells, while GATA-1 (Fig. 4B) and $N F-E 2$ (Fig. 5B) mRNA levels decreased in the ATRA-treated K562 cells compared to those in the untreated cells.
ITR-284 and ATRA regulated GATA-2 and c-MPL $m R N A$ expression. Myeloproliferative leukemia virus oncogene (c-MPL, TPO receptor) plays a crucial role in the differentiation of megakaryocytes and platelets (36-38). To determine whether ITR-284 and ATRA are involved in megakaryocyte differentiation, we treated K562 cells with either ITR-284 or ATRA for $24 \mathrm{~h}$ and examined the mRNA expression levels of GATA-2 and $c-M P L$ by quantitative RT-PCR. GATA-2 mRNA levels increased in the ITR-284-treated K562 cells (Fig. 6A), 
A

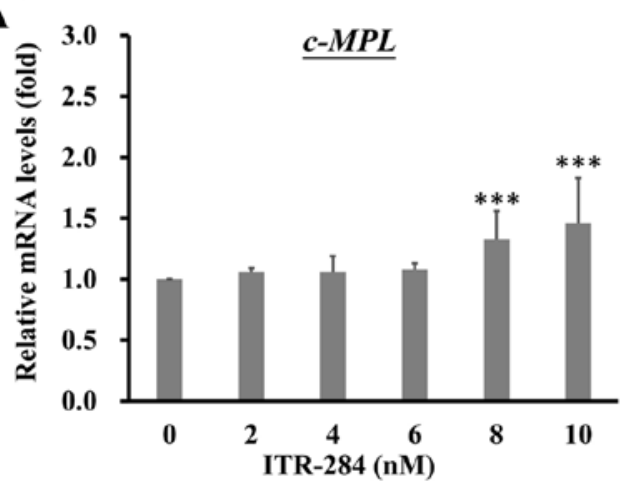

B

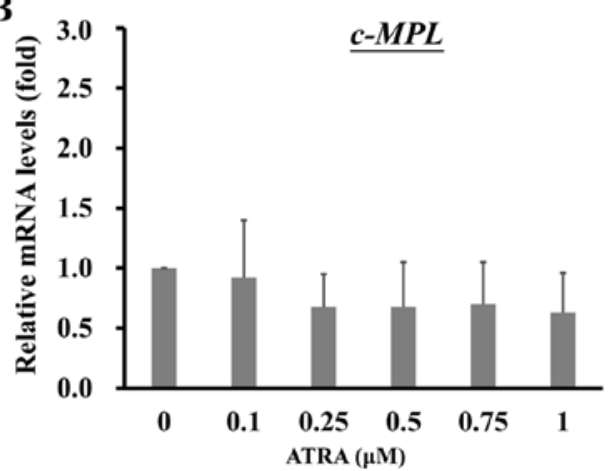

Figure 7. ITR-284 has a slight effect on the mRNA expression levels of the $c-M P L$ gene in K562 cells. K562 cells were treated with ITR-284 (A) or ATRA (B) as indicated for $24 \mathrm{~h}$. RNA samples were extracted; then, quantitative RT-PCR was performed to analyze the expression levels. No change in the $c-M P L \mathrm{mRNA}$ expression levels was detected in ITR-284-treated or ATRA-treated K562 cells $\left.{ }^{* * * *} \mathrm{p}<0.005\right)$.
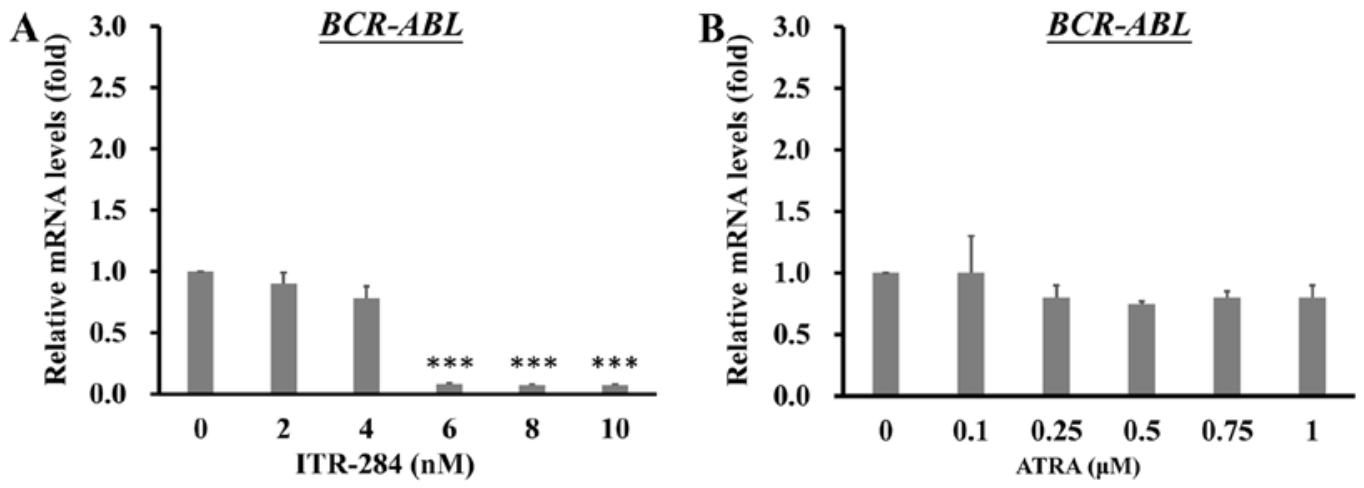

Figure 8. ITR-284 inhibits $B C R$ - $A B L$ mRNA expression levels in K562 cells. K562 cells were treated with ITR-284 (A) or ATRA (B) as indicated for $24 \mathrm{~h}$. RNA samples were extracted; then, quantitative RT-PCR was performed to analyze the expression levels. The $B C R-A B L$ mRNA expression levels were decreased in ITR-284-treated K562 cells, but no significant change was observed in ATRA-treated K562 cells ( $\left.{ }^{* * *} \mathrm{p}<0.005\right)$.

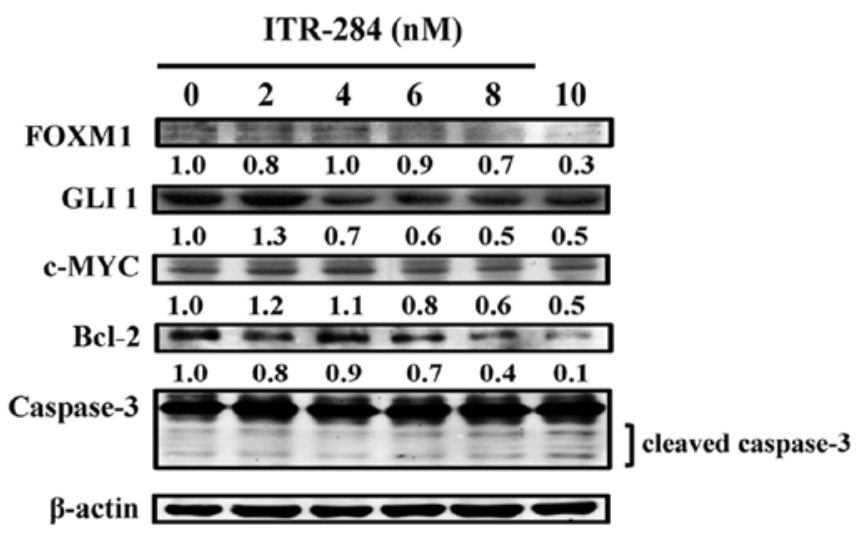

Figure 9. ITR-284 blocks tumorigenesis and triggers cell differentiation and apoptosis. K562 cells were treated with ITR-284 as indicated for $24 \mathrm{~h}$. Protein expression levels of FOXM1, GLI 1, c-MYC, BCL-2 and caspase-3 were measured by western blotting. The tumorigenesis related proteins FOXM1, GLI 1 and c-MYC were downregulated in ITR-284-treated K562 cells compared to those in untreated cells. In addition, BCL-2 and caspase-3 were also downregulated in ITR-284-treated K562 cells compared to those in untreated cells.

while GATA-2 mRNA levels decreased in the ATRAtreated K562 cells compared to those in the untreated cells (Fig. 6B). The mRNA expression levels of $c-M P L$ increased in the ITR-284-treated K562 cells (Fig. 7A), while the $c-M P L$
mRNA levels did not change in the ATRA-treated K562 cells (Fig. 7B).

ITR-284 inhibits BCR-ABL mRNA expression in K562 cells. To examine whether ITR-284 and ATRA regulate BCR-ABL mRNA expression, we treated K562 cells with either ITR-284 or ATRA for $24 \mathrm{~h}$ and measured $B C R$ - $A B L$ mRNA expression by quantitative RT-PCR. The $B C R-A B L$ mRNA levels decreased in the ITR-284-treated K562 cells (Fig. 8A), while there was no significant change in the ATRA-treated K562 cells compared to untreated cells (Fig. 8B). Our results suggest that ITR-284 inhibits BCR-ABL oncogene expression.

ITR-284 regulates cell differentiation- and apoptosis-related protein expression in $K 562$ cells. Cell differentiation- and apoptosis-related protein expression levels were analyzed. We treated K562 cells with ITR-284 for $24 \mathrm{~h}$ and measured the protein levels of forkhead box (Fox) M1 (FOXM1), GLI 1, c-MYC, BCL-2 and caspase-3 by western blotting As shown in Fig. 9, the protein levels of FOXM1, GLI 1, c-MYC and BCL-2 decreased in the ITR-284-treated K562 cells.

\section{Discussion}

Human chronic myelogenous leukemia (CML) is characterized by the presence of the Philadelphia chromosome, BCR-ABL 


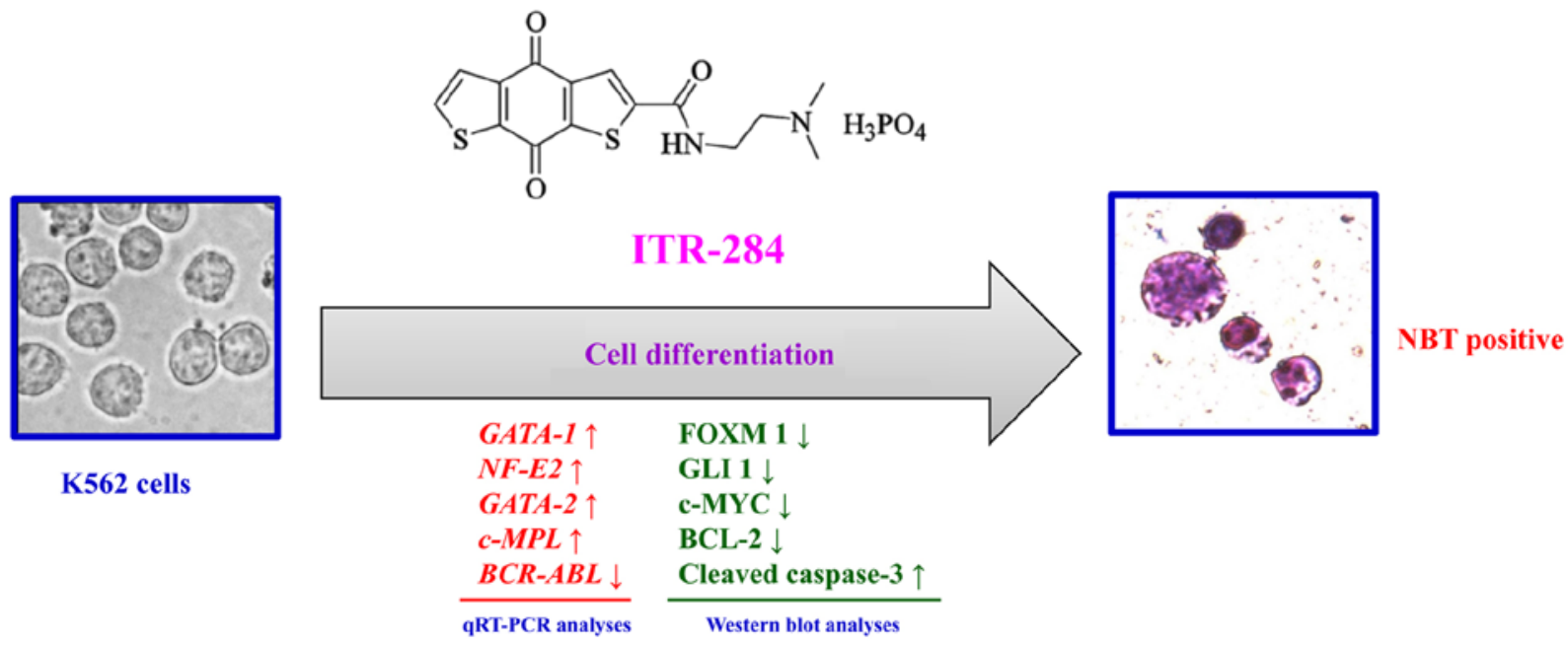

Figure 10. Possible mechanisms of action of ITR-284 in K562 cells. The diagram shows that after treatment with ITR-284, K562 cells differentiate into the erythroid lineage or the myelomonocytic lineage according to qRT-PCR and western blot analyses. Upon differentiation, the cells might trigger apoptosis.

gene fusion with the constitutively active tyrosine kinase, and increased myeloid cells in the bone marrow and the peripheral blood (3). K562 cells contain a Philadelphia chromosome with the chimeric $B C R-A B L$ gene transcript. The BCR-ABL fusion protein acts a constitutively active tyrosine kinase in malignant transformation. In recent years, target therapeutic agents have been successfully used to improve the efficacy and adverse effects observed for traditional chemotherapeutic agents $(39,40)$. Many studies have demonstrated that the novel compounds exhibit significant effects in leukemia treatment by inducing cell differentiation and apoptosis (39). The K562 cell line is a good model to investigate hematological cell differentiation and cell death. K562 cells can be differentiated to erythroid cells, macrophages and megakaryocytes by phorbol 12-myristate 13-acetate (PMA) (41,42), arsenic trioxide $\left(\mathrm{As}_{2} \mathrm{O}_{3}\right)(43,44)$ and ATRA $(45,46)$. In this study, we evaluated the anti-leukemia effects of ITR-284 on cell differentiation and investigated its mechanism of action in K562 cells. We found that ITR-284 and ATAR simultaneously induced anti-proliferation (Fig. 1), morphological changes (Fig. 2) and megakaryocytic differentiation (Fig. 3) in K562 cells according to the results of the MTT assay, May-GrünwaldGiemsa staining and nitro blue tetrazolium (NBT) assay.

Many lineage-specific transcription factors are involved in hematopoietic stem cell differentiation (47-49). The GATA transcription factor is one of the regulators of hematopoietic stem cell differentiation. GATA-1 and GATA2 bind to the consensus DNA sequence $(\mathrm{A} / \mathrm{T}) \mathrm{GATA}(\mathrm{A} / \mathrm{G})$ and regulate lineage-restricted gene expression during hematopoietic stem and progenitor cell differentiation $(47,49)$. GATA-1 is required for the differentiation of erythroid cells, granulocytic cells, mast cells, megakaryocytes, and eosinophils, whereas GATA2 is indispensable for the maintenance of hematopoietic stem and progenitor cells (49). Our results showed that GATA-1 (Fig. 4A) and GATA-2 (Fig. 6A) mRNA levels increased in the ITR-284-treated K562 cells, but GATA-2 (Fig. 6B) mRNA levels decreased in the ATRA-treated K562 cells compared to untreated cells. No report has demonstrated the exact roles of GATA-1 and GATA2 in K562 cell differentiation. Ryningen et al demonstrated that ATRA decreased the levels of GATA-2 in acute promyelocytic leukemia (APL) (50). The transcription factor nuclear factor-erythroid 2 (NF-E2) is another specific transcription factor that is functionally linked to the megakaryocytic lineage (51). It has been reported that NF-E2 was significantly reduced in malignant megakaryocytes from essential thrombocythemia (ET) patients and in K562 cells (51). The NF-E2 mRNA levels were increased in the ITR-284-treated K562 cells (Fig. 5A), suggesting that NF-E2 plays a crucial role in the ITR-284-induced differentiation of K562 cells.

Myeloproliferative leukemia virus oncogene (c-MPL, hematopoietic cytokine receptor) mainly controls the megakaryocytic lineage of cell differentiation. When K562 cells were treated with either ITR-284 or ATRA, $c$-MPL mRNA was increased (Fig. 7A). Targeting the BCR-ABL kinase is an attractive approach for CML treatment. Elevated BCR-ABL kinase activity causes cell proliferation, while the reduction of BCR-ABL kinase activity induces hematopoietic stem cell to undergo differentiation, which leads to apoptosis $(52,53)$. Our results showed that the BCR-ABL mRNA levels decreased in the ITR-284-treated K562 cells (Fig. 8A). Therefore, BCR-ABL may be a target of ITR-284.

Forkhead box (Fox) M1 (FOXM1) and c-MYC have been characterized as human proto-oncogenes and play an important role in human malignancies $(54,55)$. The FOXM1 protein, a transcriptional regulator, is involved in leukemia cell survival, proliferation and chemotherapy resistance (56-58). The c-MYC protein encodes a transcription factor that regulates the expression of various genes in cell proliferation, cell death and differentiation $(59,60)$. In this study, our results demonstrate the downregulation of the cell survival proteins FOXM1, GLI 1, c-MYC and Bcl-2. In contrast, the cleaved caspase-3 protein levels were increased in the ITR-284-treated K562 cells. These findings suggest that ITR-284 can inhibit K562 cell proliferation by inducing cell differentiation and apoptotic cell death.

In conclusion, our data showed that ITR-284 inhibits growth and cell differentiation in leukemia cells. The possible mechanisms of action of ITR-284 in K562 cells are summarized in Fig. 10. ITR-284 induces cell differentiation by upregulating 
GATA-1, NF-E2 and GATA-2, as well as $c-M P L$, and downregulating $B C R-A B L$ mRNA expression in K562 cells. Taken together, our findings provide important new insight into the possible molecular mechanism of the anti-chronic myelogenous leukemia activity of ITR-284.

\section{Acknowledgements}

This study was supported by a grant to Dr Jai-Sing Yang from China Medical University Hospital, Taichung, Taiwan (DMR-106-122). This study was supported by research grants (no. CMU100-TC-08 and no. CMU106-S-26) to Dr Shih-Chang Tsai from China Medical University, Taichung, Taiwan.

\section{References}

1. Xu LP, Wu DP, Han MZ, Huang H, Liu QF, Liu DH, Sun ZM Xia LH, Chen J, Wang HX, et al: A review of hematopoietic cell transplantation in China: Data and trends during 2008-2016. Bone Marrow Transplant: Apr 24, 2017 (Epub ahead of print). doi: $10.1038 /$ bmt.2017.59.

2. National Cancer Institute (US); Chronic myelogenous leukemia treatment: $(\mathrm{PDQ}(\mathrm{R}))$ : Health professional version. In: PDQ Cancer Information Summaries. Bethesda, MD, 2002.

3. Vrontaki E, Melagraki G, Voskou S, Phylactides MS, Mavromoustakos T, Kleanthous M and Afantitis A: Development of a predictive pharmacophore model and a 3D-QSAR study for an in silico screening of new potent Bcr-Abl kinase inhibitors. Mini Rev Med Chem 17: 188-204, 2017.

4. Webb KC, Harasimowicz M, Janeczek M, Speiser J, Swan J and Tung R: Development of asymmetric facial depigmentation in a patient treated with dasatinib with new-onset hypovitaminosis D: Case report and review of the literature. Case Rep Dermatol Med 2017: 9359086, 2017.

5. Antoszewska-Smith J, Pawlowska E and Blasiak J: Reactive oxygen species in BCR-ABL1-expressing cells - relevance to chronic myeloid leukemia. Acta Biochim Pol 64: 1-10, 2017.

6. Saponaro C, Maffia M, Di Renzo N and Coluccia AM: Is going for cure in CML targeting aberrant glycogen synthase kinase $3 \beta$ ? Curr Drug Targets 18: 396-404, 2017.

7. Haguet H, Douxfils J, Mullier F, Chatelain C, Graux C and Dogné JM: Risk of arterial and venous occlusive events in chronic myeloid leukemia patients treated with new generation BCR-ABL tyrosine kinase inhibitors: A systematic review and meta-analysis. Expert Opin Drug Saf 16: 5-12, 2017.

8. Huang WW, Yang JS, Lin CF, Ho WJ and Lee MR: Pycnogenol induces differentiation and apoptosis in human promyeloid leukemia HL-60 cells. Leuk Res 29: 685-692, 2005.

9. Saleh M, Shamsasanjan K,Movassaghpour AA, AkbarzadehlalehP and Molaeipour Z: Inhibitory effect of mesenchymal stem cell co-culture on erythroid differentiation of K562 cells compared to the control croup. Cell J 19: 127-136, 2017.

10. Zhu Y, Wang D, Wang F, Li T, Dong L, Liu H, Ma Y, Jiang F, Yin H, Yan W, et al: A comprehensive analysis of GATA-1regulated miRNAs reveals miR-23a to be a positive modulator of erythropoiesis. Nucleic Acids Res 41: 4129-4143, 2013.

11. Nishimura S, Takahashi S, Kuroha T, Suwabe N, Nagasawa T, Trainor C and Yamamoto M: A GATA box in the GATA-1 gene hematopoietic enhancer is a critical element in the network of GATA factors and sites that regulate this gene. Mol Cell Biol 20 713-723, 2000.

12. Raich N and Romeo PH: Erythroid regulatory elements. Stem Cells 11: 95-104, 1993.

13. Gourdon G, Morlé F, Roche J, Tourneur N, Joulain V and Godet J: Identification of GATA-1 and NF-E2 binding sites in the flanking regions of the human alpha-globin genes. Acta Haematol 87: 136-144, 1992.

14. Ayala RM, Martínez-López J, Albízua E, Diez A and Gilsanz F: Clinical significance of Gata-1, Gata-2, EKLF, and c-MPL expression in acute myeloid leukemia. Am J Hematol 84: 79-86, 2009.

15. Jordan CT and Van Zant G: Recent progress in identifying genes regulating hematopoietic stem cell function and fate. Curr Opin Cell Biol 10: 716-720, 1998.
16. Honeycutt KA and Roop DR: c-Myc and epidermal stem cell fate determination. J Dermatol 31: 368-375, 2004.

17. de Nigris F, Sica V, Herrmann J, Condorelli G, Chade AR, Tajana G, Lerman A, Lerman LO and Napoli C: c-Myc oncoprotein: Cell cycle-related events and new therapeutic challenges in cancer and cardiovascular diseases. Cell Cycle 2: 325-328, 2003.

18. Pan XN, Chen JJ, Wang LX, Xiao RZ, Liu LL, Fang ZG, Liu Q, Long ZJ and Lin DJ: Inhibition of c-Myc overcomes cytotoxic drug resistance in acute myeloid leukemia cells by promoting differentiation. PLoS One 9: e105381, 2014.

19. Wu Y, Yang Y, Meng W, Li Y, Jia Y and Liu T: Study on the differentiation of K562 cell-line induced by Tanshinone II A. Hua Xi Yi Ke Da Xue Xue Bao 33: 80-83, 2002 (In Chinese).

20. Yang $Y$ and Yang M: Effects of C-myc antisense transcripts on differentiation of k562 cells. Int J Oncol 6: 419-424, 1995.

21. Sasaki D, Kosunago S, Mikami T, Matsumoto T and Suzuki M: Growth-inhibition by hemin in K562 human leukemic cells is related to hemoglobin-producing activity. Biol Pharm Bull 17: 586-590, 1994.

22. Liu N, Li P, Zang S, Liu Q, Ma D, Sun X and Ji C: Novel agent nitidine chloride induces erythroid differentiation and apoptosis in CML cells through c-Myc-miRNAs axis. PLoS One 10: e0116880, 2015.

23. Gómez-Casares MT, García-Alegria E, López-Jorge CE, Ferrándiz N, Blanco R, Alvarez S, Vaqué JP, Bretones G, Caraballo JM, Sánchez-Bailón P, et al: MYC antagonizes the differentiation induced by imatinib in chronic myeloid leukemia cells through downregulation of p27(KIP1). Oncogene 32: 2239-2246, 2013

24. Kawano T, Horiguchi-Yamada J, Saito S, Iwase S, Furukawa Y, Kano Y and Yamada H: Ectopic cyclin D1 expression blocks STI571-induced erythroid differentiation of K562 cells. Leuk Res 28: 623-629, 2004.

25. Chang CH, Lee CY, Lu CC, Tsai FJ, Hsu YM, Tsao JW, Juan YN, Chiu HY, Yang JS and Wang CC: Resveratrol-induced autophagy and apoptosis in cisplatin-resistant human oral cancer CAR cells: A key role of AMPK and Akt/mTOR signaling. Int J Oncol 50: 873-882, 2017

26. Liao YR, Lu CC, Lai KC, Yang JS, Kuo SC, Wen YF, Fushiya S and Wu TS: The novel carboxamide analog ITR-284 induces caspase-dependent apoptotic cell death in human hepatocellular and colorectal cancer cells. Mol Med Rep 7: 1539-1544, 2013.

27. Wen YF, Yang JS, Kuo SC, Hwang CS, Chung JG, Wu HC, Huang WW, Jhan JH, Lin CM and Chen HJ: Investigation of anti-leukemia molecular mechanism of ITR-284, a carboxamide analog, in leukemia cells and its effects in WEHI-3 leukemia mice. Biochem Pharmacol 79: 389-398, 2010.

28. Huang SM, Yang JS, Tsai SC, Chen MH, Hsu MH, Lin HY, Chou LC, Chinag JH, Lee KH, Huang LJ, et al: The novel synthesized 2-(3-(methylamino)phenyl)-6-(pyrrolidin-1-yl) quinolin-4-one (Smh-3) compound induces G2/M phase arrest and mitochondrial-dependent apoptotic cell death through inhibition of CDK1 and AKT activity in HL-60 human leukemia cells. Int J Oncol 38: 1357-1364, 2011.

29. Chen HY, Lu HF, Yang JS, Kuo SC, Lo C, Yang MD, Chiu TH, Chueh FS, Ho HC, Ko YC, et al: The novel quinolone CHM-1 induces DNA damage and inhibits DNA repair gene expressions in a human osterogenic sarcoma cell line. Anticancer Res 30: 4187-4192, 2010

30. Liu CY, Yang JS, Huang SM, Chiang JH, Chen MH, Huang LJ, Ha HY, Fushiya S and Kuo SC: Smh-3 induces G(2)/M arrest and apoptosis through calcium-mediated endoplasmic reticulum stress and mitochondrial signaling in human hepatocellular carcinoma Hep3B cells. Oncol Rep 29: 751-762, 2013.

31. Lin C, Tsai SC, Tseng MT, Peng SF, Kuo SC, Lin MW, Hsu YM, Lee MR, Amagaya S, Huang WW, et al: AKT serine/threonine protein kinase modulates baicalin-triggered autophagy in human bladder cancer T24 cells. Int J Oncol 42: 993-1000, 2013.

32. Song QF, Qu YC, Zheng HB, Zhang GH, Lin HG and Yang JL: Differentiation of erythroleukemia K562 cells induced by piperine Ai Zheng 27: 571-574, 2008 (In Chinese).

33. Gu C, Yang Y, Sompallae R, Xu H, Tompkins VS, Holman C, Hose D, Goldschmidt H, Tricot G, Zhan F, et al: FOXM1 is a therapeutic target for high-risk multiple myeloma. Leukemia 30 : 873-882, 2016.

34. Liao CL, Lai KC, Huang AC, Yang JS, Lin JJ, Wu SH, Gibson Wood W, Lin JG and Chung JG: Gallic acid inhibits migration and invasion in human osteosarcoma U-2 OS cells through suppressing the matrix metalloproteinase-2/-9, protein kinase $\mathrm{B}$ (PKB) and PKC signaling pathways. Food Chem Toxicol 50: 1734-1740, 2012. 
35. Lin CF, Yang JS, Lin C, Tsai FJ, Lu CC and Lee MR: CCY-1a-E2 induces $\mathrm{G} 2 / \mathrm{M}$ phase arrest and apoptotic cell death in HL-60 leukemia cells through cyclin-dependent kinase 1 signaling and the mitochondria-dependent caspase pathway. Oncol Rep 36: 1633-1639, 2016.

36. Deutsch VR and Tomer A: Megakaryocyte development and platelet production. Br J Haematol 134: 453-466, 2006.

37. Hofmann WK, Ottmann OG and Hoelzer D: Megakaryocytic growth factors: Is there a new approach for management of thrombocytopenia in patients with malignancies? Leukemia 13 : 14-18, 1999.

38. Katayama N, Itoh R, Kato T, Sugawara T, Mahmud N, OhishiK, Masuya M, Aoki M, Minami N, Miyazaki H, et al: Role for C-MPL and its ligand thrombopoietin in early hematopoiesis. Leuk Lymphoma 28: 51-56, 1997.

39. Chi HT, Ly BT, Kano Y, Tojo A, Watanabe T and Sato Y: ETV6-NTRK3 as a therapeutic target of small molecule inhibitor PKC412. Biochem Biophys Res Commun 429: 87-92, 2012.

40. Huang YC, Shieh HR and Chen YJ: Midostaurin (PKC412) modulates differentiation and maturation of human myeloid dendritic cells. Toxicol In Vitro 24: 1705-1710, 2010.

41. Anisimov AG, Volkova TO, Chekmasova AA and Nemova NN Phorbol-12-myristate-13-acetate prevents the inhibitory effect of A23187 on erythroid differentiation of K562 cells induced by dimethylsulfoxide. Izv Akad Nauk Ser Biol: 142-148, 2002 (In Russian).

42. Lee CH, Yun HJ, Kang HS and Kim HD: ERK/MAPK pathway is required for changes of cyclin D1 and B1 during phorbol 12-myristate 13-acetate-induced differentiation of K562 cells. IUBMB Life 48: 585-591, 1999.

43. Yuan FF, Zhang XH, Mi RH, Fan RH, Yin QS and Wei XD: Effects of $\mathrm{As}_{2} \mathrm{O}_{3}$ in combination with TPA on K562 cells Zhongguo Shi Yan Xue Ye Xue Za Zhi 22: 943-949, 2014 (In Chinese)

44. Xu W, Wei W, Yu Q, Wu C, Ye C, Wu Y and Yan H: Arsenic trioxide and bortezomib interact synergistically to induce apoptosis in chronic myelogenous leukemia cells resistant to imatinib mesylate through $\mathrm{Bcr} / \mathrm{Abl}$-dependent mechanisms. Mol Med Rep 10: 1519-1524, 2014

45. Xiang L, Dong W, Wang R, Wei J, Qiu G, Cen J, Chen Z, Zheng X, Hu S, Xie X, et al: All-trans retinoic acid enhances the effect of 5-aza-2'-deoxycytidine on p16INK4a demethylation, and the two drugs synergistically activate retinoic acid receptor $\beta$ gene expression in the human erythroleukemia K562 cell line. Oncol Lett 8: 117-122, 2014.

46. Tang XY, Wang CH and Xiao GF: The effect of ATRA-induced leukemic cell differentiation on Brd7 gene expression in leukemia cell lines. Zhongguo Shi Yan Xue Ye Xue Za Zhi 18: 593-596, 2010 (In Chinese)

47. Sive JI and Göttgens B: Transcriptional network control of normal and leukaemic haematopoiesis. Exp Cell Res 329: 255-264, 2014
48. Ebina W and Rossi DJ: Transcription factor-mediated reprogramming toward hematopoietic stem cells. EMBO J 34: 694-709, 2015.

49. Shimizu R and Yamamoto M: GATA-related hematologic disorders. Exp Hematol 44: 696-705, 2016.

50. Ryningen A, Stapnes C, Paulsen K, Lassalle P, Gjertsen BT and Bruserud O: In vivo biological effects of ATRA in the treatment of AML. Expert Opin Investig Drugs 17: 1623-1633, 2008.

51. Catani L, Vianelli N, Amabile M, Pattacini L, Valdrè L, Fagioli ME, Poli M, Gugliotta L, Moi P, Marini MG, et al: Nuclear factor-erythroid 2 (NF-E2) expression in normal and malignant megakaryocytopoiesis. Leukemia 16: 1773-1781, 2002.

52. Fierro FA, Taubenberger A, Puech PH, Ehninger G, Bornhauser M, Muller DJ and Illmer T: BCR/ABL expression of myeloid progenitors increases beta1-integrin mediated adhesion to stromal cells. J Mol Biol 377: 1082-1093, 2008.

53. Chen GQ, Wang LS, Wu YL and Yu Y: Leukemia, an effective model for chemical biology and target therapy. Acta Pharmacol Sin 28: 1316-1324, 2007.

54. Zhang Z, Zhu P, Zhou Y, Sheng Y, Hong Y, Xiang D, Qian Z, Mosenson $\mathrm{J}$ and $\mathrm{Wu}$ WS: A novel slug-containing negativefeedback loop regulates $\mathrm{SCF} / \mathrm{c}$-Kit-mediated hematopoietic stem cell self-renewal. Leukemia 31: 403-413, 2017.

55. Green MR, Aya-Bonilla C, Gandhi MK, Lea RA, Wellwood J, Wood P, Marlton P and Griffiths LR: Integrative genomic profiling reveals conserved genetic mechanisms for tumorigenesis in common entities of non-Hodgkin's lymphoma. Genes Chromosomes Cancer 50: 313-326, 2011.

56. Mencalha AL, Binato R, Ferreira GM, Du Rocher B and Abdelhay E: Forkhead box M1 (FoxM1) gene is a new STAT3 transcriptional factor target and is essential for proliferation, survival and DNA repair of K562 cell line. PLoS One 7: e48160, 2012.

57. Carrett-Dias M, Almeida LK, Pereira JL, Almeida DV, Filgueira DM, Marins LF, Votto AP and Trindade GS: Cell differentiation and the multiple drug resistance phenotype in human erythroleukemic cells. Leuk Res 42: 13-20, 2016.

58. Nakamura S, Hirano I, Okinaka K, Takemura T, Yokota D, Ono T, Shigeno K, Shibata K, Fujisawa S and Ohnishi K: The FOXM1 transcriptional factor promotes the proliferation of leukemia cells through modulation of cell cycle progression in acute myeloid leukemia. Carcinogenesis 31: 2012-2021, 2010.

59. Shin JM, Jeong YJ, Cho HJ, Magae J, Bae YS and Chang YC Suppression of c-Myc induces apoptosis via an AMPK/mTORdependent pathway by 4-O-methyl-ascochlorin in leukemia cells. Apoptosis 21: 657-668, 2016

60. Shi P, Huang Z and Chen G: Rhein induces apoptosis and cell cycle arrest in human hepatocellular carcinoma BEL-7402 cells. Am J Chin Med 36: 805-813, 2008. 